\title{
Systematic review of continuous self-improvement interventions
}

\author{
Michelle L. Matteson ${ }^{1}$, Cynthia L. Russell ${ }^{2}$ \\ 1. Sinclair School of Nursing, University of Missouri, Columbia, USA. 2. School of Nursing, University of Missouri-Kansas \\ City, USA.
}

Correspondence: Michelle Matteson, Address: Division of Gastroenterology and Hepatology, University of Missouri, 101 Fairview, Columbia, M065203, USA. Email: mattesonml@health.missouri.edu

Received: November 29, 2012

Accepted: January 16, 2013

Online Published: February 1, 2013

DOI : $10.5430 /$ cns.v1n1p10

URL: http://dx.doi.org/10.5430/cns.v1n1p10

\begin{abstract}
Although health care providers advise healthy and chronically ill adults to adopt positive health behaviors, traditional interventions focused on motivation and intention have been largely ineffective. Researchers have tested the ability of continuous self-improvement (CSI), an innovative personal system-based intervention, to affect health behavior change at the individual level. This paper systematically reviews CSI interventions focused on improving health behaviors. A search of multiple databases was performed using 'continuous self-improvement' as the search term. Abstracts of identified studies were reviewed to determine if CSI was used as an intervention-regardless of sample size, study type, or language. This review identified nine studies testing the CSI intervention in healthy or chronically ill adults. Effect sizes for the two randomized controlled trials were large. CSI shows promise as an effective intervention across a broad age range for a variety of difficult-to-change behaviors. Future research should address methodologic weaknesses.
\end{abstract}

\section{Key words}

Continuous Self-Improvement, Systematic review, Interventions, Health behavior change

\section{Introduction}

Health care providers routinely advise healthy and chronically ill adults to adopt positive health behaviors to improve the

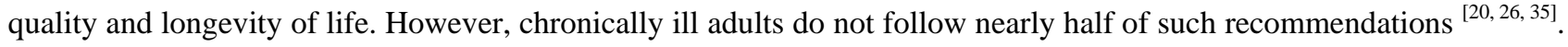
Although intervention research has attempted to enhance these health-promoting behaviors through motivation and intention, changing health behaviors is difficult, complex, and largely ineffective ${ }^{[8]}$. Researchers have tested the ability of continuous self-improvement (CSI), an innovative personal system-based intervention, to affect health behavior change at the individual level. This paper systematically reviews CSI interventions focused on improving health behaviors.

The costs of health behavior change failure are high. For example, if medication nonadherence rates increase, subsequent increases in morbidity and mortality may occur. Medication nonadherence results in decreased quality of life and productivity, increased medical costs due to hospitalization, and increased morbidity and mortality ${ }^{[45,14,42]}$.

Health behavior change interventions have focused primarily at the patient level by enhancing motivation and intention through cognitive, affective, and associated behavioral strategies. Cognitive interventions impart knowledge, whereas 


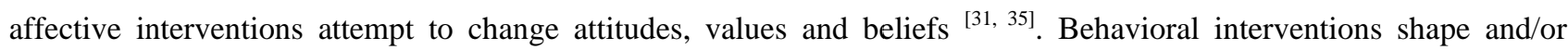
reinforce behavior ${ }^{[31]}$.

Health behavior change interventions directed toward individuals have had little effect in enhancing medication adherence $^{[35,26,20,10,24,31,6]}$. For example, medication or disease education (cognitive interventions) had no significant impact on medication adherence when presented in the traditional brochure-type fomat ${ }^{[6,35,31]}$. Affective interventions focusing on social support, beliefs, intentions, and motivation have not been effective ${ }^{[7]}$. The effect sizes of cognitive, behavioral, and affective interventions are inconsistent and weak (Chronic Disease Interventions and Effect Sizes, Figure 1).

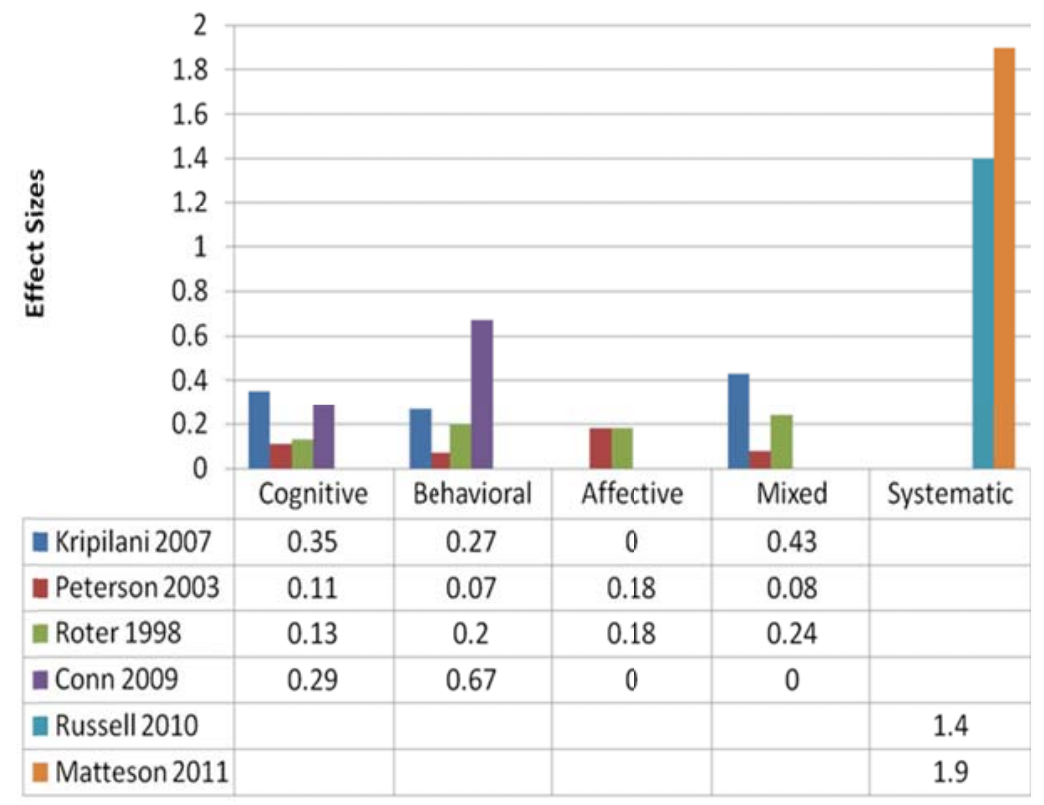

Figure 1. Chronic disease interventions and effect sizes

In summary, health behavior change interventions based on motivation or intention directed at individuals have shown inconsistent results. Research focusing on the personal systems operating within an individual's environment has not been systematically evaluated. This review addresses a knowledge gap by systematically appraising the Continuous Self Improvement (CSI) intervention literature. This systematic evaluation will guide clinicians and researchers regarding the degree of effectiveness of personal systems-based interventions, an approach that departs from traditional health behavior-change interventions.

\section{Background}

Systems-based interventions have been used with continuous quality improvement (CQI) principles that Deming initiated in the 1950 's in the manufacturing sector ${ }^{[11]}$. CQI is a data-driven, system-based intervention for optimizing productivity and decreasing system error. In the 1980s, CQI began to revolutionize the health care industry. Applying CQI principles in hospitals has decreased system-based errors and improved patient care ${ }^{[15,30,33]}$.

Based on the successes in organizational system change in the manufacturing and health care industries, Alemi, Pawloski, and Fallon (2003) postulated that CQI principles could improve exercise and eating behaviors at the personal systems level. Alemi established that personal habits are a function not of motivation but rather of environment, and published a 
guide to assist people in personal system-based changes to improve health behaviors ${ }^{[1]}$. Personal system thinking is conceptually defined as the process of understanding how people and circumstances are linked ${ }^{[2]}$. Alemi and colleagues called this approach Continuous Self-improvement (CSI). CSI is a personal system-focused intervention to change behavior by influencing the environmental system in which the individual functions (his or her personal system). This approach does not blame the individual's lack of behavior change and/or maintenance but rather focuses on improving the system that creates and maintains the behavior ${ }^{[1,17,38]}$. Through a data evaluation and system refinement process called Plan-Do-Check-Act (PDCA), personal system changes are identified and implemented; health behaviors become ritualistic and habitual, with less effort, motivation, and intention required to maintain the desired health behavior change.

Plan-Do-Check-Act (PDCA) is one tool employed by the CSI framework to assist in testing of the intervention and is the cornerstone of the CSI process. Other important tools include those to assess the system (fishbone, process diagrams, and Pareto charts) and those that measure variation (run charts and control charts). System tools are used prior to initiating PDCA. CSI is a comprehensive personal quality improvement approach to system change, in which the person functions by utilizing system tools and PDCA. Data derived from the PDCA cycles optimize the quality of the system ${ }^{[11,27]}$. The individual PDCA concepts are defined by Deming as follows: Plan involves identifying and analyzing the individual's environmental system leading to desired change. Do is the implementation of identified systems changes. Check determines the effectiveness of the system change by monitoring the desired change. Act evaluates the effectiveness of the system change based on the individual's desired change. At this juncture, the individual can adopt the solution, abandon it, or reprocess the solution through the PDCA cycle again. The cycles continue until the system is optimized and the desired health behavior change is achieved and maintained.

Alemi proposes four mechanisms in the framework: "the system is the cause of change; habits involve linked decisions; process owners need to join in supporting change; system change is based on data" (p. 81) ${ }^{[2]}$. The first assumption of continuous self-improvement is that the system is the cause of the behavior ${ }^{[2]}$. Since individual behavior occurs within a system, any change in that system results in a change in behavior; Berwick (1996) wrote, "Every system is perfectly designed to achieve the results it achieves" (p. 619) ${ }^{[5]}$. These systems can be purposefully altered to achieve the desired change. Personal systems can create negative health behavior, and therefore the system must change at the personal level to influence the desired behavior. Alemi et al. (2000) state "discipline and will power are not a personality trait, but a function of the environment in which the individual functions ... motivation itself is manipulated, engineered, or influenced by the system with which the persona has surrounded himself or herself' (p. 81). Although this framework removes blame from individuals, they remain responsible for participating in care or accountable for selecting the environment that produces the behavior ${ }^{[2]}$. This personal system approach is consistent with a recent World Health Organization's report on adherence, which suggests that shifting blame from the patient to his or her environment may enhance adherence ${ }^{\text {[41] }}$.

The second assumption is that habits involve linked decisions ${ }^{[2]}$. A habit is a repeated pattern of behavior that is predictable and ingrained; at times person is unaware the behavior was performed ${ }^{[18]}$. According to Deming, improvement is not a single effort ${ }^{[48]}$. Rather, a decision influences the decision before it and the decision that follows it. Repeating a series of linked decisions over time forms a habit. Examining the personal system allows one to see existing habits and to identify possible changes in these linked decisions. Systems change is meant to be a coil of continuous motion. Within the dynamic health care system, improvement must be a continuous process, always striving for better system outcomes ${ }^{[12]}$.

The third assumption of CSI is that process owners need to join in supporting change. "Knowledge of the dynamic relationships of the system and the people that work in it are necessary to manage the system effectively" (p. 97) ${ }^{[48]}$. When others are involved in the personal system, their "touch" or involvement is essential to affect change ${ }^{[2]}$. Their impact on the system must be analyzed systematically. This prerequisite knowledge enhances the system assessment, leading to better interventions, and ultimately improves behavior. 
The fourth assumption is that system change is based on data. Systems are improved by collecting and careful analyzing objective data. These data, which should measure the targeted behavior, should be systematically gathered, organized, and reviewed by those involved in the system change. "In God we trust, all others must use data," (p. 96) ${ }^{[48]}$. The CSI framework is based on data collected by the individual and the healthcare team. The data are not based on assumptions, emotions, or experience ${ }^{[47,48]}$. Data are used to assess the system, monitor success, and evaluate the interventions. No change can be achieved without data derived from the system; change without data is opinion.

In summary, health behavior change interventions (cognitive, behavioral, and affective) have shown inconsistent and weak results when directed towards individuals. Shifting the focus of health behavior change research to CSI, a personal systems based intervention, may yield effective health behavior change. The purpose of this review is to analyze the CSI literature to date, and address the lack of information on this innovative health behavior change intervention.

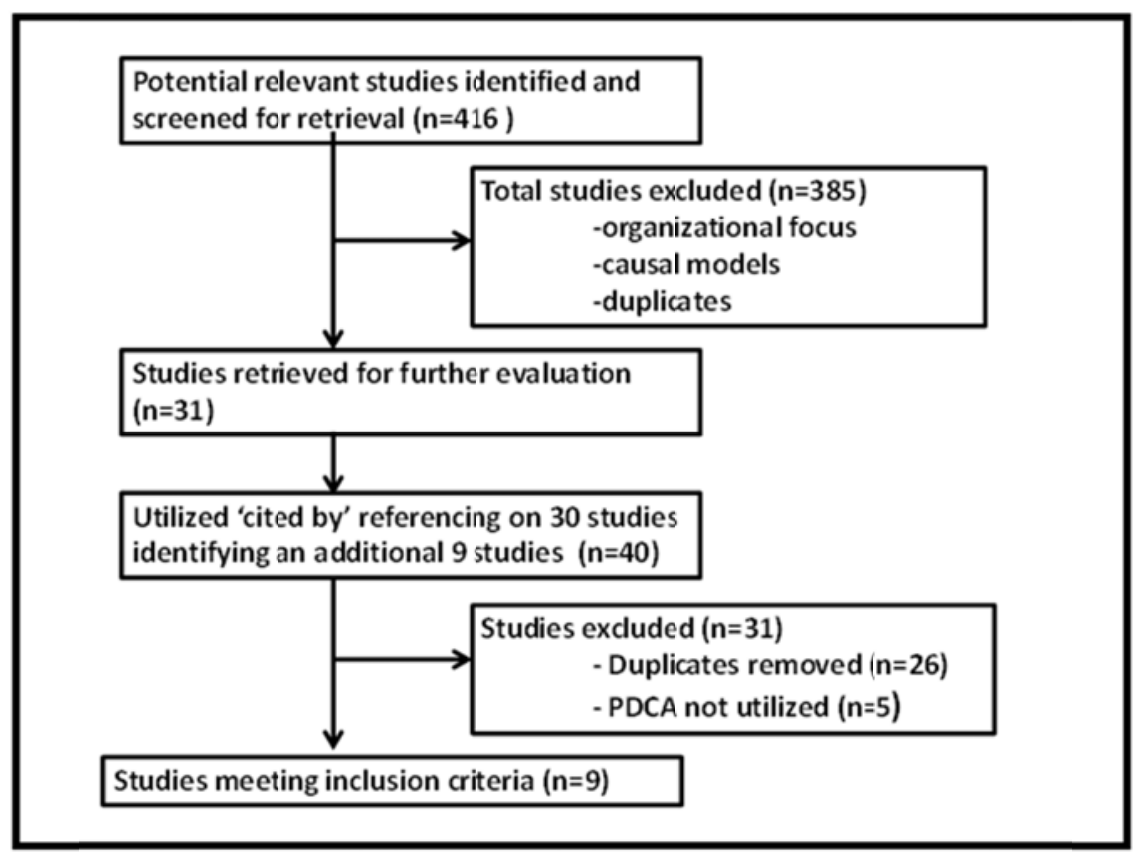

Figure 2. Study Inclusion Flow Chart

\section{Methods}

A search of Cumulative Index of Nursing and Allied Health Literature (CINAHL) (1982- May 2011), MEDLINE (1950May 2011), PsycINFO (1806-May 2011), Google Scholar, Scopus, ProQuest Dissertation \& Theses A \& I, and all Evidence-Based Medicine (EBM) Reviews (Cochran DSR, ACP Journal Club, DARE, CCTR) was conducted to identify studies testing the CSI intervention in healthy or chronically ill adults. The search term 'continuous self-improvement' with no limits set on search terms. In addition to the broad search, literature published by key CSI expert authors was also searched. The seminal articles of key authors were then subjected to the "cited by" function on all search engines. This maneuver identified studies that referenced these seminal studies. Retrieved abstracts were reviewed for inclusion. No limitations were set on the original search in order to identify the greatest number of studies utilizing CSI. Inclusion criteria were any studies utilizing CSI as an intervention regardless of study type, sample size or language. Nine studies met inclusion criteria (see Figure 2). Data from the nine studies were extracted, including: author and year, sample/setting, study design, intervention description (dose, duration), theoretical constructs, measures/outcomes, results, methodological strengths and weaknesses, and STROBE/CONSORT scoring. STROBE criteria are criteria to report observational studies 
and CONSORT criteria are for randomized controlled trials ${ }^{[10,43,46]}$. Although STROBE and CONSORT criteria were designed to be used as guidelines to improve the reporting of research in manuscripts, De Bleser and colleagues used them as quality indicators of the methodological rigor ${ }^{[43,46]}$. Data review was performed and agreed upon by both authors.

Table 1. CSI Literature Review Table

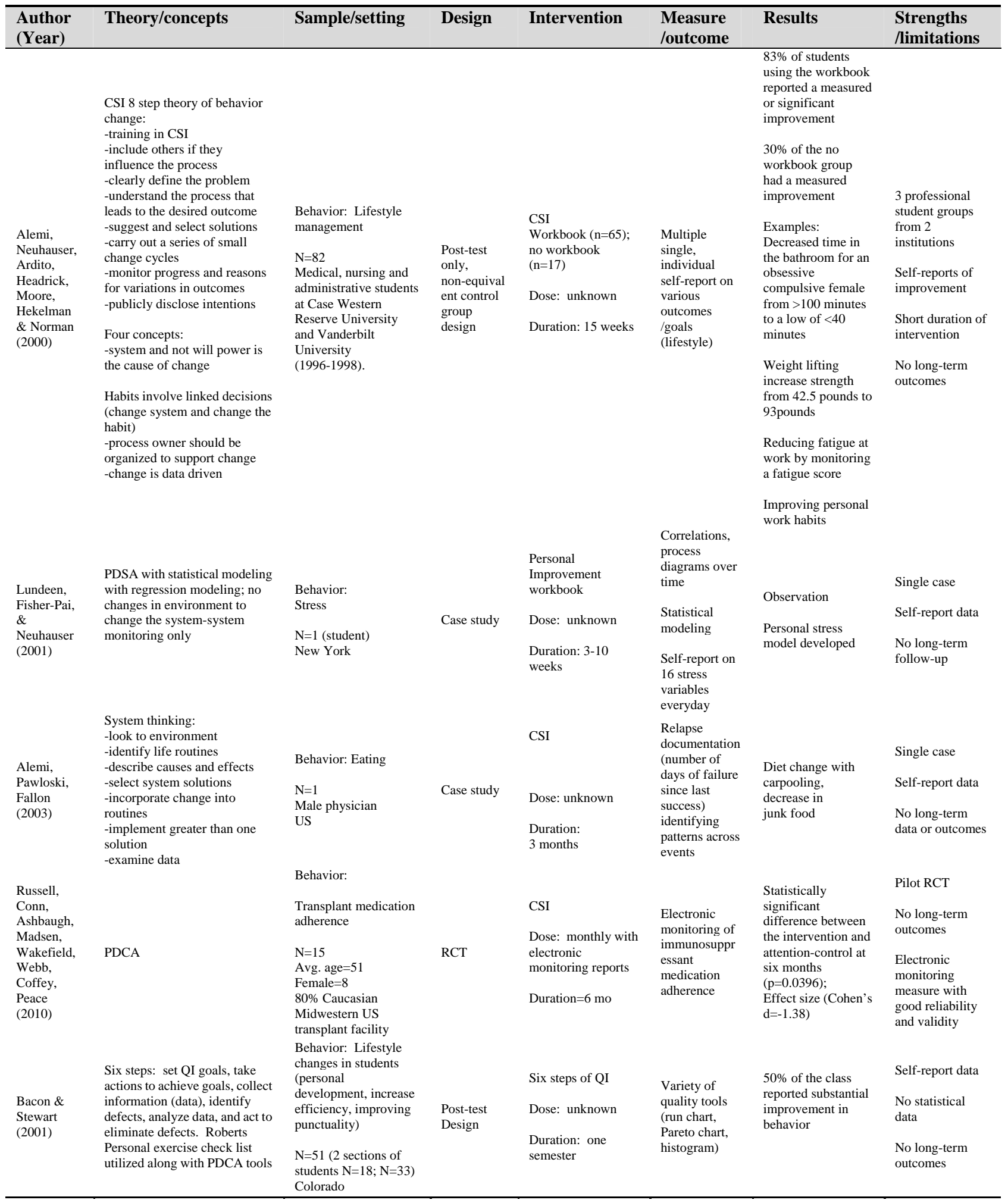


Table 1. (Continued.)

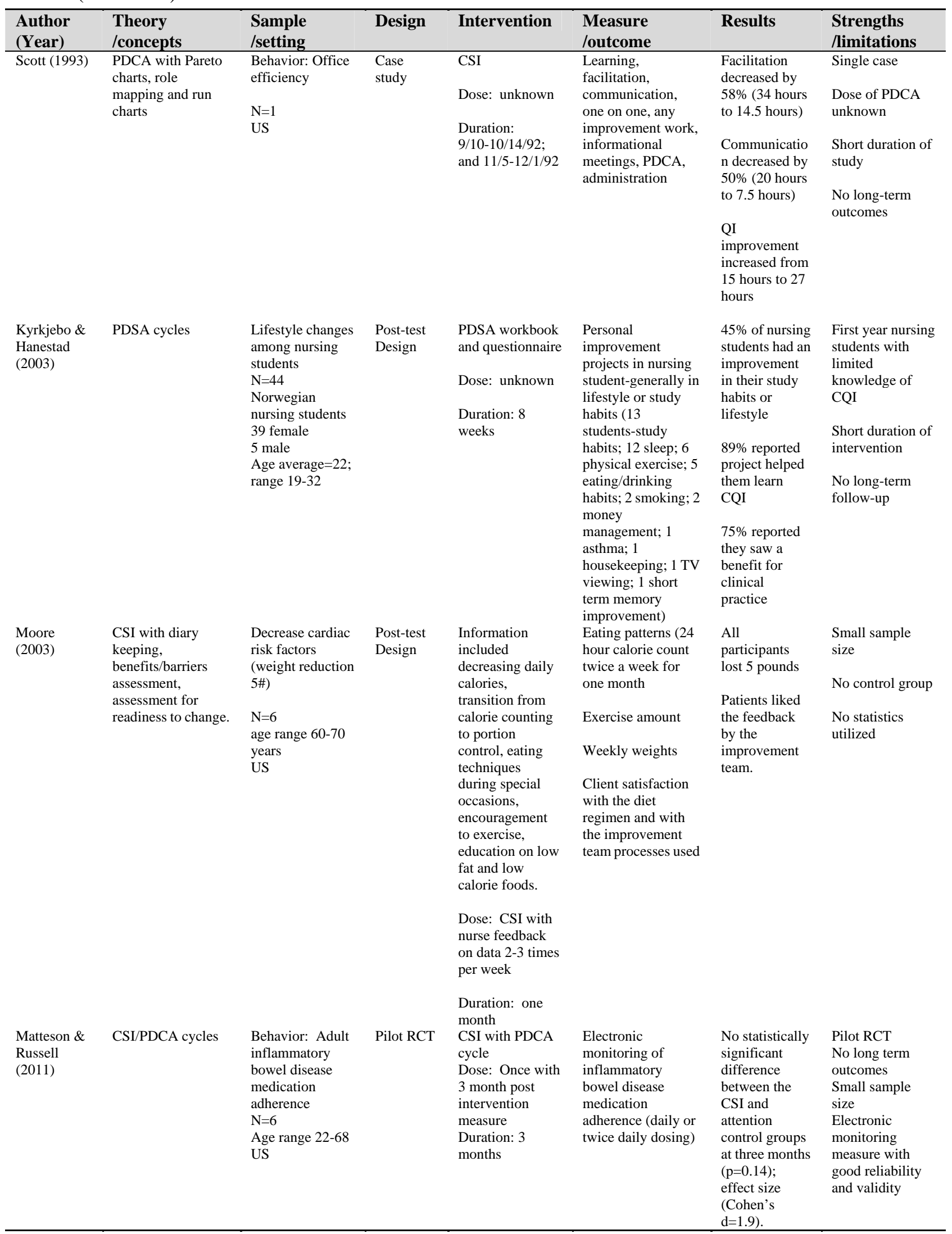


Table 2. CONSORT scoring ( $0=$ =not documented; $0.5=$ =partially documented; $1=$ documented $)$

\begin{tabular}{|c|c|c|c|c|}
\hline & & & $\begin{array}{l}\text { Russell } \\
2010\end{array}$ & $\begin{array}{l}\text { Matteson } \\
2011\end{array}$ \\
\hline \multirow[t]{2}{*}{1} & Title \& abstract & $\begin{array}{l}\text { How participants were allocated to interventions (e.g. random allocation, randomized or } \\
\text { randomly assigned) }\end{array}$ & 1 & 1 \\
\hline & Introduction & & & \\
\hline \multirow[t]{2}{*}{2} & Background & Scientific background and explanation of rationale & 1 & 1 \\
\hline & Methods & & & \\
\hline 3 & Participants & $\begin{array}{l}\text { Eligibility criteria for participants and the settings and locations where the data were } \\
\text { collected }\end{array}$ & 1 & 1 \\
\hline 4 & Interventions & $\begin{array}{l}\text { Precise details of the interventions intended for each group and how and when they were } \\
\text { actually administered }\end{array}$ & 1 & 1 \\
\hline 5 & Objectives & Specific objectives and hypotheses & 0.5 & 1 \\
\hline 6 & Outcomes & $\begin{array}{l}\text { Clearly defined primary and secondary outcome measures and, when applicable, any } \\
\text { methods used to enhance the quality of measurements (e.g. Multiple observations, training of } \\
\text { assessors) }\end{array}$ & 1 & 1 \\
\hline \multirow[t]{2}{*}{7} & Sample Size & $\begin{array}{l}\text { How sample size was determined and, when applicable, explanation of any interim analyses } \\
\text { and stopping rules }\end{array}$ & 1 & 1 \\
\hline & Randomization & & & \\
\hline 8 & $\begin{array}{l}\text { Sequence } \\
\text { generation }\end{array}$ & $\begin{array}{l}\text { Method used to generate the random allocation sequence, including details of any restriction } \\
\text { (e.g. blocking, stratification) }\end{array}$ & 1 & 1 \\
\hline 9 & $\begin{array}{l}\text { Allocation } \\
\text { concealment }\end{array}$ & $\begin{array}{l}\text { Method used to implement the random allocation sequence (e.g. Numbered containers or } \\
\text { central telephone), clarifying whether the sequence was concealed until interventions were } \\
\text { assigned }\end{array}$ & 0 & 1 \\
\hline 10 & Implementation & $\begin{array}{l}\text { Who generated the allocation sequence, who enrolled participants, and who assigned } \\
\text { participants to their groups }\end{array}$ & 0.5 & 1 \\
\hline 11 & $\begin{array}{l}\text { Blinding } \\
\text { (masking) }\end{array}$ & $\begin{array}{l}\text { Whether or not participants, those administrating the interventions, and those assessing the } \\
\text { outcomes were blinded to group assignment. If done, how the success of blinding was } \\
\text { evaluated }\end{array}$ & 1 & 1 \\
\hline 12 & $\begin{array}{l}\text { Statistical } \\
\text { methods } \\
\text { Results }\end{array}$ & $\begin{array}{l}\text { Statistical methods used to compare groups for primary outcome(s); methods for additional } \\
\text { analyses, such as subgroup analyses and adjusted analyses. }\end{array}$ & 1 & 1 \\
\hline 13 & Participant flow & $\begin{array}{l}\text { Flow of participants through each stage (a diagram is strongly recommended). Specifically, } \\
\text { for each group report the numbers of participants randomly assigned, receiving intended } \\
\text { treatment, completing the study protocol, and analyzed for the primary outcome. Describe } \\
\text { protocol deviations from study as planned, together with reasons. }\end{array}$ & 1 & 1 \\
\hline 14 & Recruitment & Dates defining the periods of recruitment and follow-up. & 1 & 1 \\
\hline 15 & Baseline data & Baseline demographic and clinical characteristics of each group. & 1 & 1 \\
\hline 16 & $\begin{array}{l}\text { Numbers } \\
\text { analyzed }\end{array}$ & $\begin{array}{l}\text { Number of participants (denominator) in each group included in each analysis and whether } \\
\text { the analysis was by intention to treat. State the results in absolute numbers when feasible } \\
\text { (e.g. } 10 / 20 \text {, not } 50 \% \text { ) }\end{array}$ & 1 & 1 \\
\hline 17 & $\begin{array}{l}\text { Outcomes and } \\
\text { estimation }\end{array}$ & $\begin{array}{l}\text { For each primary and secondary outcome, a summary of results for each group, and the } \\
\text { estimated effect size and its precision (e.g. } 95 \% \text { confidence interval) }\end{array}$ & 1 & 1 \\
\hline 18 & $\begin{array}{l}\text { Ancillary } \\
\text { analyses }\end{array}$ & $\begin{array}{l}\text { Address multiplicity by reporting any other analyses performed, including subgroup } \\
\text { analyses and adjusted analyses, indicating those pre-specified and those exploratory. }\end{array}$ & 1 & 0 \\
\hline \multirow[t]{2}{*}{19} & Adverse events & All important adverse events of side effects in each intervention group & 0.5 & 1 \\
\hline & Discussion & & & \\
\hline 20 & Interpretation & $\begin{array}{l}\text { Interpretation of the results, taking into account study hypotheses, sources of potential bias } \\
\text { or imprecision and the dangers associated with multiplicity of analyses and outcomes }\end{array}$ & 1 & 1 \\
\hline 21 & Generalizability & Generalizability (external validity) of the trial findings & 1 & 1 \\
\hline \multirow[t]{2}{*}{22} & Overall evidence & General interpretation of the results in the context of current evidence & 1 & 1 \\
\hline & Total score & & 19.5 & 21 \\
\hline
\end{tabular}




\section{Results}

\subsection{Descriptions of studies}

Sample: Nine studies were eligible for inclusion (see Figure 2). The published studies ranged in date from 1993 to $2011^{[24,44]}$, with all but one published after the year 2000. Sample sizes ranged from 1 to 82 participants, whose ages ranged from 19 to $70^{[2,3,23,44]}$. Eight studies were performed in the United States and one in Norway ${ }^{[21]}$. Three of the nine studies were performed in academic settings with the aim of teaching quality improvement principles of CQI to students $^{[2,4,21]}$. Six studies focused on healthy adults attempting to enhance personal lifestyle improvement such as studying, eating, exercise, work habits, and stress ${ }^{[2,3,4,21,23,44]}$. In the remaining three studies focusing on chronically ill adults, CSI was utilized to augment kidney transplantation immunosuppression medication adherence ${ }^{[38]}$, to decrease cardiac risk factors through weight loss ${ }^{[29]}$, and enhance medication adherence in people with inflammatory bowel disease

${ }^{[25]}$. Data from included studies are reported in Table 1 (CSI Systematic Review of Included Studies).

\subsection{Design}

Three studies used a case study design ${ }^{[23,3,44]}$, three a post-test design ${ }^{[4,21,29]}$, one a post-test non-equivalent control group design ${ }^{[2]}$, and two randomized controlled trial (RCT) design ${ }^{[38,25]}$. STROBE criteria are utilized for manuscript report for non-experimental studies ${ }^{[46]}$; CONSORT scoring criteria are used for manuscript reporting for RCT's ${ }^{\text {[4] }}$. Data for STROBE and CONSORT scoring were gathered from the studies by one reviewer (MM) and verified for accuracy by a second reviewer (CR); discrepancies were discussed and mutually agreed upon. Scoring of the STROBE and CONSORT criteria consisted of 0 (not documented), 0.5 (partially documented), or 1.0 (documented); lower scores indicate less documentation or methodological rigor ${ }^{[10]}$. Studies with CONSORT scores from 0 to 7 are classified as weak, 8 to 16 as moderately strong studies, and 17 to 22 as strong ${ }^{[10]}$. CONSORT scoring details are found in Table 2 and STROBE scoring details in Table 3. Reporting of the seven non-experimental studies ranged from weak to moderate (7.0-16.0 out of $22)^{[2-4,21,23,29,44]}$. The study detail reporting was weak or less precise, implying weak methodological rigor. CONSORT scoring was performed on the two RCT's meeting our study inclusion criteria, and the reporting was found to be strong (19.5 and 21 out of 22), indicating stronger methodological rigor ${ }^{[38,25]}$.

\subsection{I ntervention concepts}

Use of the PDCA concepts within the nine studies varied slightly. Although eight studies used PDCA, three studies identified this process as PDSA (Plan-Do-Study-Act) ${ }^{[21,23,29]}$. The authors used Check interchangeably with Study. Bacon and Stewart (2001) used a six-step process for system change (set quality improvement goals, take actions to achieve goals, collect information using data, identify defects, analyze data, act to eliminate defects). Despite small differences, all aspects of the cycle were present in all of the studies.

Plan involves identifying and analyzing the individual's environmental system ${ }^{[11,38]}$. All nine studies included this step, though one author used a slightly different description. Bacon and Stewart (2001) described the 'Plan' step as setting personal improvement goals to be accomplished in the projected time period followed by development of a tracking form to follow progress.

The second step, $D o$, is the implementation of identified systems changes ${ }^{[11,38]}$. Only eight studies clearly specified the 'Do' step; but all nine studies utilized such a step. Bacon and Stewart (2001) describe the 'Do' step as taking actions to achieve goals set in the 'Plan' step. Taking action is similar to 'doing,' performing or working on a task. 'Check' is the next step in the cycle and is.

All nine studies used the Check step, which was where most of the subtle differences existed. The name of the step varied,

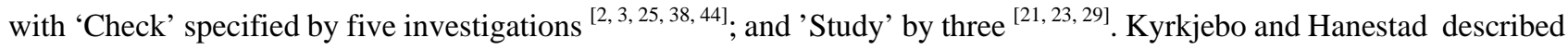
'Study' as data analysis, comparing data to predictions, and summarizing what is learned, which is very similar to 
Deming's 'Check,' which is examining and determining the state of the system ${ }^{[11,38]}$. Bacon and Stewart (2001) defined this step as identifying defects, analyzing data, and identifying patterns of defects; similarly, Bacon and Stewart (2001) defined this step as examining the personal system data by checking or studying the system.

Table 3. STROBE scoring

\begin{tabular}{|c|c|c|c|c|c|c|c|c|c|}
\hline & $\begin{array}{l}\text { Item } \\
\text { No }\end{array}$ & Recommendation & $\begin{array}{l}\text { Alemi } \\
(2000)\end{array}$ & $\begin{array}{l}\text { Lundeen } \\
\text { (2001) }\end{array}$ & $\begin{array}{l}\text { Alemi } \\
(2003)\end{array}$ & $\begin{array}{l}\text { Bacon } \\
(2001)\end{array}$ & $\begin{array}{l}\text { Scott } \\
(1993)\end{array}$ & $\begin{array}{l}\text { Kyrkjebo } \\
\text { (2003) }\end{array}$ & $\begin{array}{l}\text { Moore } \\
(2003)\end{array}$ \\
\hline \multirow[t]{2}{*}{$\begin{array}{l}\text { Title and } \\
\text { abstract }\end{array}$} & 1 & $\begin{array}{l}\text { (a) Indicate the study's design with a } \\
\text { commonly used term in the title or the } \\
\text { abstract }\end{array}$ & 0 & 0.5 & 0 & 0 & 0.5 & 0 & 0 \\
\hline & & $\begin{array}{l}\text { (b) Provide in the abstract an } \\
\text { informative and balanced summary of } \\
\text { what was done and what was found }\end{array}$ & 0 & 0.5 & 0 & 0 & 0 & 1 & 0 \\
\hline \multicolumn{10}{|l|}{ Introduction } \\
\hline $\begin{array}{l}\text { Background } \\
\text { /rationale }\end{array}$ & 2 & $\begin{array}{l}\text { Explain the scientific background and } \\
\text { rationale for the investigation being } \\
\text { reported }\end{array}$ & 1 & 1 & 1 & 1 & 1 & 1 & 1 \\
\hline Objectives & 3 & $\begin{array}{l}\text { State specific objectives, including any } \\
\text { prespecified hypotheses }\end{array}$ & 1 & 1 & 0 & 0 & 1 & 1 & 0.5 \\
\hline Study design & 4 & $\begin{array}{l}\text { Present key elements of study design } \\
\text { early in the paper }\end{array}$ & 0 & 0.5 & 0.5 & 0.5 & 0 & 0 & 0.5 \\
\hline Setting & 5 & $\begin{array}{l}\text { Describe the setting, locations, and } \\
\text { relevant dates, including periods of } \\
\text { recruitment, exposure, follow-up, and } \\
\text { data collection }\end{array}$ & 0 & 1 & 0.5 & 0 & 1 & 1 & 0.5 \\
\hline Participants & 6 & $\begin{array}{l}\text { Case-control study-Give the } \\
\text { eligibility criteria, and the sources and } \\
\text { methods of case ascertainment and } \\
\text { control selection. Give the rationale for } \\
\text { the choice of cases and controls }\end{array}$ & 0 & 0.5 & 0.5 & 0.5 & 0 & 0 & 0.5 \\
\hline Variables & 7 & $\begin{array}{l}\text { Clearly define all outcomes, } \\
\text { exposures, predictors, potential } \\
\text { confounders, and effect modifiers. } \\
\text { Give diagnostic criteria, if applicable }\end{array}$ & 0.5 & 1 & 0.5 & 0.5 & 1 & 1 & 0.5 \\
\hline $\begin{array}{l}\text { Data sources } \\
\text { /measurement }\end{array}$ & $8^{*}$ & $\begin{array}{l}\text { For each variable of interest, give } \\
\text { sources of data and details of methods } \\
\text { of assessment (measurement). } \\
\text { Describe comparability of assessment } \\
\text { methods if there is more than one } \\
\text { group }\end{array}$ & 0.5 & 1 & 1 & 0.5 & -- & 1 & 0.5 \\
\hline Bias & 9 & $\begin{array}{l}\text { Describe any efforts to address } \\
\text { potential sources of bias }\end{array}$ & 0.5 & 0.5 & 0.5 & 0.5 & 0 & 0.5 & 0.5 \\
\hline Study size & 10 & $\begin{array}{l}\text { Explain how the study size was arrived } \\
\text { at }\end{array}$ & 0 & 0 & 0 & 0.5 & 0.5 & 1 & 1 \\
\hline $\begin{array}{l}\text { Quantitative } \\
\text { variables }\end{array}$ & 11 & $\begin{array}{l}\text { Explain how quantitative variables } \\
\text { were handled in the analyses. If } \\
\text { applicable, describe which groupings } \\
\text { were chosen and why }\end{array}$ & 0 & 1 & 0 & 0.5 & 0.5 & 1 & 0.5 \\
\hline \multirow[t]{5}{*}{$\begin{array}{l}\text { Statistical } \\
\text { methods }\end{array}$} & 12 & $\begin{array}{l}\text { (a) Describe all statistical methods, } \\
\text { including those used to control for } \\
\text { confounding }\end{array}$ & 0 & 1 & 0 & 0.5 & 0.5 & 1 & 0.5 \\
\hline & & $\begin{array}{l}\text { (b) Describe any methods used to } \\
\text { examine subgroups and interactions }\end{array}$ & 0 & 0 & 0 & 0 & 0 & 0 & 0 \\
\hline & & $\begin{array}{l}\text { (c) Explain how missing data were } \\
\text { addressed }\end{array}$ & 0 & 0 & 0 & 0 & 0 & 0 & 0 \\
\hline & & $\begin{array}{l}\text { (d) Case-control study-If applicable, } \\
\text { explain how matching of cases and } \\
\text { controls was addressed }\end{array}$ & 0 & 0 & 0 & 0 & 0 & 0 & 0 \\
\hline & & (e) Describe any sensitivity analyses & 0 & 0 & 0 & 0 & 0 & 0 & 0 \\
\hline
\end{tabular}


Table 3. (Continued.)

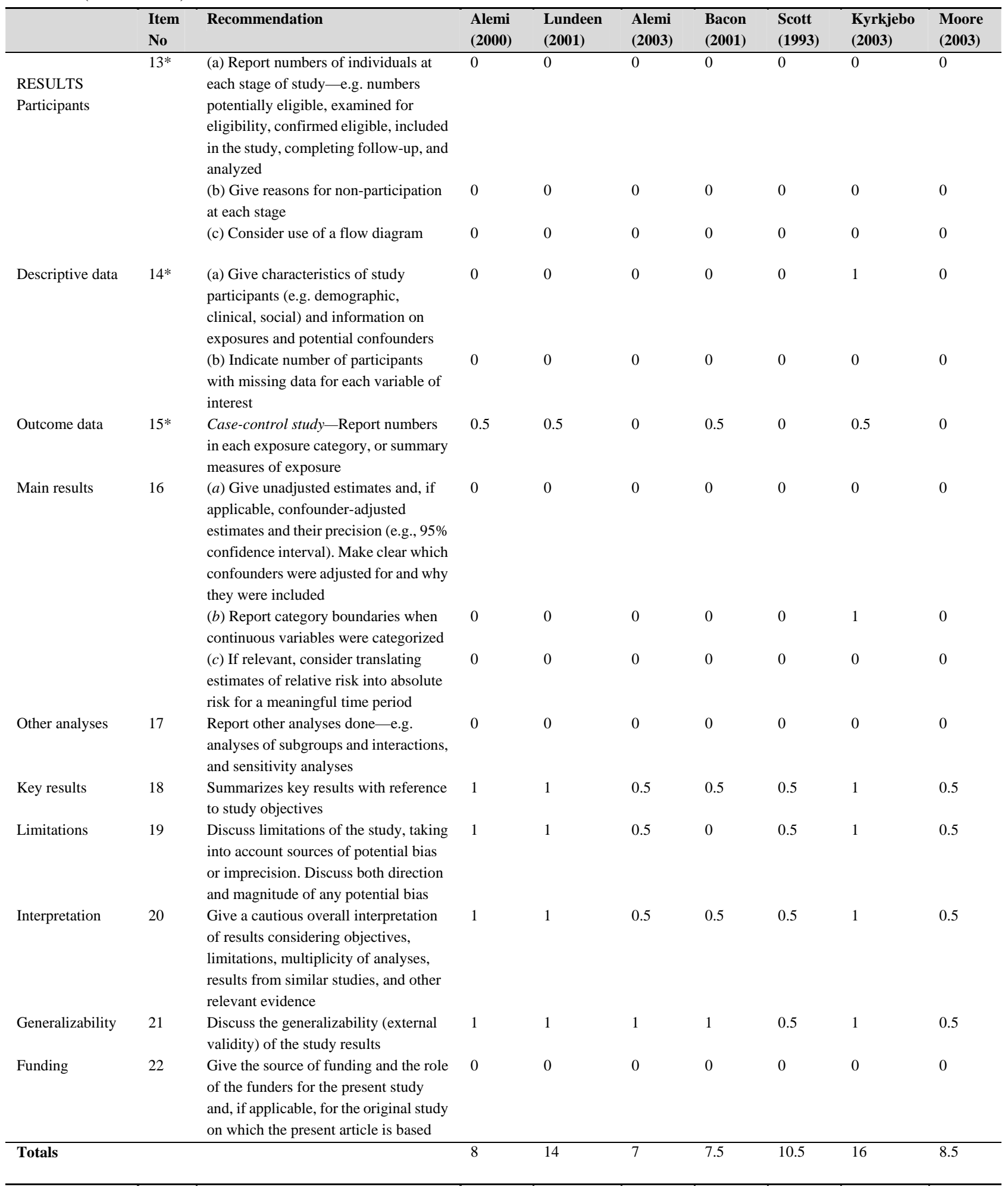

Note: STROBE Statement—checklist of items that should be included in reports of observational studies

The final stage, Act, involves evaluating the effectiveness of the system change, determining whether to adopt the solution, abandon it, or reprocess the solution through the cycle again ${ }^{[11,38]}$. All nine studies specified 'Act' as the cycle's final part; Bacon and Stewart (2001) described 'Act' as understanding and eliminating defects and realizing goals. The remaining seven studies defined 'Act' as evaluating the change and determining effectiveness ${ }^{[11,38]}$. 


\subsection{Methods guiding personal improvement}

Authors used various data collection tools within the 'Check' step of the PDCA cycle, including flow charts, fishbone diagrams, Pareto charts, histograms, and/or run charts. These varied tools facilitated visualization and analysis of data. A flow chart is a diagram of the system processes that shows how one event leads to another ${ }^{[1,48]}$. A fishbone diagram is a fishbone-shaped cause-and-effect diagram used in brainstorming sessions to identify system factors influencing a behavior ${ }^{[48]}$. A Pareto chart is a common graphic tool that uses bars in descending order to represent individual values and a line in ascending order to represent the cumulative total value. Histograms use bars representing values over a discrete time period to identify behavior frequency; and a run chart displays data in sequence over time using dots and lines ${ }^{[48]}$. For example, Alemi and colleagues (2003) used the Pareto chart to examine a person's poor eating behavior. Within the participant's personal system, the Pareto chart prioritized leaving late from work as the major influence on junk food intake. With data from the Pareto chart, the participant changed his system changes by changing driving behavior. He participated in a carpool that left work daily at the same time. This personal system change was key to improving eating behaviors. In another example, two studies ${ }^{[25,38]}$ used the MEMS report which delineates colored dots for each day and time the MEMS is opened and a medication is presumed administered.

Three studies utilized Alemi and Neuhauser’s 2006 CSI workbook, which marks the origin of the CSI movement ${ }^{[2,21,23]}$. The workbook guides personal system change problem solving to help the general public manage body weight. The workbook's step-by-step personal system approach helps improve diet and exercise behaviors by training readers to study their personal systems using data collection tools such as routine analysis, flow charts, and PDCA cycles. Lundeen et al. (2001) utilized the workbook in addition to statistical modeling with regression to identify her personal system processes that could be improved to change her behavior and improve her symptoms.

\subsection{I ntervention dose}

Five studies did not document the CSI intervention dose. Documented dose frequencies ranged from once ${ }^{[25]}$, to monthly ${ }^{[38]}$. The duration of interventions ranged from four weeks ${ }^{[29]}$ to six months ${ }^{[38]}$. One study documented a single CSI dose with a three month monitoring period ${ }^{[25]}$; none of the remaining studies documented long-term follow up or long-term outcomes.

\subsection{Measurement}

The change in the targeted behavior was the primary outcome evaluated in the included studies which included lifestyle changes, stress, weight loss, work habits, and medication adherence. Seven studies measured the targeted behavior using self-report. The authors of the seven studies utilizing self-report did not report reliability or validity data of their self-report tools, which limits the interpretation and strength of the data. Objective and accurate data assesses the system, monitors success, and evaluates the intervention; therefore data accuracy is vital to the PDCA system. Behaviors were measured using relapse documentation ${ }^{[3]}$, the Roberts personal checklist ${ }^{[4]}$, and 24-hour calorie counts and weekly weights ${ }^{[29]}$. The Roberts personal checklist was utilized by Bacon and Stewart to focus on "a goal-directed behavior," which motivational theorists say can lead to behavior change (p. 72). The checklist assists in goal setting, identifying defects and specific variables to monitor defects ${ }^{[4]}$.

The remaining two studies utilized electronic monitoring of medication-taking behavior (Medication Event Monitoring System [MEMS], Aprex Corp., Union City, CA, USA) ${ }^{[28]}$ as the adherence outcome measure ${ }^{[25,38]}$. The MEMS uses a cap for medication bottles whose electronic chip measures the date and time of cap removal ${ }^{[28]}$. The cap has good reliability and has been used in over 500 studies ${ }^{[34]}$. The electronic monitoring is shown to have a failure rate below $0.5 \%$ and less than a $2 \%$ malfunction rate ${ }^{[13,39]}$. 


\subsection{Results}

All nine CSI intervention studies demonstrated improved behavioral outcomes in their targeted samples. Improved outcomes included lifestyle changes, stress, weight loss, work habits, and medication adherence.

Of the six studies dealing with lifestyle changes in healthy adults, three were performed with college students. Alemi et al. (2000) found that $83 \%$ of students reported a "measured or significant improvement" in their individual lifestyle projects (p. 84). Bacon and Stewart (2001) found a 50\% improvement in students' lifestyle behaviors, whereas Kyrkjebo and Hanestad (2003) found that $45 \%$ of nursing students showed an improvement in their lifestyle behaviors. The remaining three lifestyle studies in healthy adults dealt with stress, weight loss, and work habits. Lundeen et al. (2001) utilized PDCA to identify stress as the underlying problem with her symptoms of indigestion, food intolerance, back and abdominal pain, pounding heart, and inability to sleep. Alemi et al. (2003) found participating in a carpool led to decrease the amount of junk food ingested, which contributed to weight loss. Scott (1993) enhanced his productivity as a Quality Improvement (QI) manager by identifying situations in which his QI expertise was not needed. He decreased work group facilitation by $58 \%$ and communication by $50 \%$ and so was able to concentrate his QI expertise where it was most useful.

The three remaining studies were performed with chronically ill adults. Moore's (2003) CSI intervention focused on individuals meeting a five-pound weight loss goal. All six participants met their goal and appreciated the feedback from the process improvement team. Russell et al.’s (2010) CSI intervention for adult kidney transplant adults showed a statistically significant improvement in immunosuppressant medication adherence between the CSI treatment and attention-control ( $\mathrm{p}=0.0376)$ groups at six months; a large effect size (Cohen's $\mathrm{d}=-1.38$ ) was also found. A study by Matteson et al. (2011), a CSI intervention for inflammatory bowel disease adults, showed no statistically significant results $(p=0.14)$ between the CSI and attention control groups at three months, but a very large effect size (Cohen's $d=1.9)$ was found.

\section{Discussion}

The purpose of this systematic review of literature was to investigate CSI intervention research across reports from healthy and chronically ill adults and to determine the potential for CSI as a health behavior change intervention. Our review of the nine studies from the last 17 years indicates that CSI shows promise as an intervention for changing health behavior outcomes based on the effect sizes of the two randomized controlled studies. These findings should be considered preliminary due to the studies' methodological weaknesses.

The strength of this review is that it addresses a gap in the behavior change intervention literature. Although CQI has been an effective process improvement tool for more than 60 years in business and healthcare ${ }^{[11]}$, enhancing health behavior change may require a paradigm shift to apply CQI to personal system improvement. Data supporting the effectiveness of CSI are preliminary, but show promise as a health behavior change intervention, as evidenced by the large effect sizes found in the two RCT's utilizing CSI.

Interventionists could employ CSI to address numerous health behaviors needing change in the clinical setting. Numerous qualified interventionists may be available because most healthcare providers have participated in quality improvement (QI) projects in medical or nursing education or training ${ }^{[19,22,49]}$. Patient safety and QI are core concepts for practice and for involvement in institutional improvement plans ${ }^{[19,22,49]}$. With CSI mentorship, healthcare providers may be able to transition their QI experience into the clinical arena. Whether addressing weight loss, smoking cessation or medication adherence, all of these health behaviors could be amenable to personal system changes through CSI, as evidenced by the recent pilot RCT utilizing CSI in the clinical arena. 
This familiarity with continuous quality improvement tools such as PDCA across multiple disciplines and patients may help translate CSI from the organizational to the personal level. Several opportunities exist for learning about and using CSI. Alemi and Neuhauser (2006) published A Thinking Person's Weight Loss and Exercise Program to help lay persons apply CSI principles to their lives. University courses are available to students in the area of process improvement ${ }^{[16)}$. Healthcare professionals familiar with CSI are testing its use to improve health behaviors. Nursing and Medical schools across the country have utilized CQI to improve students' performance through practice-based learning, which applies these skills to practice settings.

Early indications are that patients become engaged in CSI and are capable of learning its techniques when taught by healthcare professionals ${ }^{[40]}$. Participants are able to understand the CSI process with the healthcare professional acting as the mentor or CSI coach when the participant finds a lack of improvement in their targeted behavior. Although participants' age was absent in several reviewed articles, older adults who self-administer medications may benefit from CSI. For example, an older adult who self-administers medications may enhance medication taking behaviors through CSI; however, residents in assisted living facilities may have multiple people touching their system, potentially having less impact on the desired medication taking behaviors.

Limitations of the reviewed studies include weak designs, small sample sizes, single center studies, limited dose and duration of the intervention, use of instruments with questionable reliability and validity, and lack of long-term outcomes. Methodologic quality was poor for most studies. Case study design, one of the weakest study designs, was used in three of the reports ${ }^{[32]}$. The STROBE scores of these studies were weak to moderate, indicating lower methodological and reporting rigor; whereas the CONSORT scoring of the two RCT's was strong, reflecting the study's methodological and reporting strengths.

The second limitation of the reviewed studies is lack of statistical power. Since sample size affects studies' statistical power, the effect intervention studies that are not fully powered may not be adequately tested or realized ${ }^{[32]}$. Though the study by Russell et al. (2010) was not powered to detect a difference between groups, the study did find a statistically significant difference between the groups, which supports the large effect size of the CSI personal improvement intervention. The study by Matteson et al. (2011) had a small sample size and was not adequately powered to find a statistically significant difference; however, the study found a large effect size.

Third, the dose and duration of the interventions were brief, which may limit their effectiveness. Doses and durations have been evaluated for only a few time periods. Future research should evaluate small and large doses and long and short durations to determine the right CSI combinations for the best outcome.

Fourth, the instruments used to evaluate the outcomes could have been stronger. To enable future meta-analysis of CSI studies, outcome measurement needs to be more consistent across studies. Medication adherence is an intermediate outcome; other outcomes influenced by medication adherence may be measured including biological, psychological, and social outcomes. For example, adherence outcomes for those with kidney transplant could include creatinine, acute and chronic rejection, kidney loss, and death ${ }^{[37]}$.

Despite these limitations, CSI shows promise as a behavior change intervention based on the nine studies reviewed. Russell et al. (2010) found the CSI intervention was effective immediately, which indicates that providers may be able to deliver it brief patient encounters. Matteson et al. (2011) found with a single dose of CSI delivered in the clinical setting had a very large effect size.

Fourth, no long-term outcomes were documented in the nine reviewed studies. The longest follow-up time period was six months. The extent of human and financial resources needed to maintain the behavior is also unknown. Finally, seven of the studies employed self-report instruments. Self-report depends on patients' honesty and recall. If self-report data are gathered during interviews, then the interviewer's skill also is a variable that can influence data validity and reliability. 
Overall, the results of this systematic review of the CSI intervention research thus far have been trending in the direction of CSI effectiveness as evidenced by the two RCT's large effect sizes. Most nurses have been involved in CQI projects during their education or practice; therefore, nurses' familiarity with organizational system change can be easily adapted and applied to patients' personal systems. In inpatient or outpatient settings that include nursing practice, nurses could easily implemented CSI to affect health behavior change regarding medication adherence, weight management, and smoking cessation. With further experience and research, confidence in CSI as an intervention could continue to expand and evidence strengthened.

\section{Conclusion}

In conclusion, CQI has long been used successfully at the organizational level. During the past few years, researchers have investigated CSI as a health behavior change intervention for individuals. Although this review found that CSI may have promise as a behavior change intervention, the methodological quality of the reviewed studies is weak. More fully powered randomized controlled trials with diverse populations and long term follow-up are needed to further study the effectiveness of the CSI intervention.

\section{References}

[1] Alemi F, Neuhauser D(Eds.). A thinking person's weight loss and exercise program. Fairfax, Virginia: George Mason University.2006.

[2] Alemi F, Neuhauser D, Ardito S, Headrick L, Moore R, Hekelman F,Norman L. Continuous self-improvement: Systems thinking in a personal context. Journal on Quality Improvement. 2000;26(2): 74-86.

[3] Alemi F, Pawloski L, Fallon WF. System thinking in a personal context to improve eating behaviors. Journal for Healthcare Quality.2003; 25(2): 20-25. PMid:12659076 http://dx.doi.org/10.1111/j.1945-1474.2003.tb01040.x

[4] Bacon DR, Stewart KA. The personal data analysis exercise. Journal of Management Education.2001;25(1):70-78. http://dx.doi.org/10.1177/105256290102500107

[5] Berwick DM. A primer on leading the improvement of systems. British Medical Journal.1996; 312(7031): 619-22. PMid:8595340 http://dx.doi.org/10.1136/bmj.312.7031.619

[6] Conn V, Hafdahl A, Cooper P, Ruppar T, Mehr D, Russell C. Interventions to improve medication adherence among older adults: Meta-analysis of adherence outcomes among randomized controlled trials. The Gerontologist. 2009. PMid:19460887 http://dx.doi.org/10.1093/geront/gnp037

[7] Conn VS, Valentine JC,Cooper HM. Inteventions to increase physical activity among aging adults, Annals of Behavioral Medicine. 2002; 24(3):190-200. PMid:12173676 http://dx.doi.org/10.1207/S15324796ABM2403_04

[8] Conn VS. Internet-based interventions to change health behaviors. Western Journal of Nursing Research.2010; 32(1): 3-4. PMid:20164473 http://dx.doi.org/10.1177/0193945909348464

[9] Conn VS, Hafdahl AR,Mehr DR. Interventions to increase physical activity among healthy adults: Meta-analysis of outcomes. American Journal of Public Health. 2011. Epub 2/19/2011.

[10] De Bleser L, Matteson ML, Dobbels F, Russell C, De Geest S. Interventions to improve medication-adherence after transplantation: A systematic review. Transplant International. 2009:1-18.

[11] Deming WE. Out of the Crisis. Cambridge, MA: Massachusetts Institute of Technology.1986.

[12] Deming WE. The New Economics: For Industry, Government, and Education. Cambridge, MA: Massachusetts Institutes of Technology; 1994.

[13] Denhaerynck K, Schafer-Keller P, Young J, Steiger J, Bock A, De Geest S. Examining assumptions regarding valid electronic monitoring of medication therapy: development of a validation framework and its application on a European sample of kidney transplant patients. BMC Medical Research Methodology.2008; 8: 5. http://dx.doi.org/10.1186/1471-2288-8-5

[14] Dew MA, DiMartini AF, De Vito Dabbs A, Myaskovsky L, Steel J, Unruh M, Switzer GE, Zomak R, Kormos RL, Greenhouse JB. Rates and risk factors for nonadherence to the medical regimen after adult solid organ transplantation. Transplantation.2007; 83(7): 858-873. PMid:17460556 http://dx.doi.org/10.1097/01.tp.0000258599.65257.a6

[15] Edmonds J, Zagami M. QI team shares ownership and gets results. Journal of Healthcare Quality.1992;14(5): 24-28. http://dx.doi.org/10.1111/j.1945-1474.1992.tb00231.x 
[16] George Washington University. University Bulletin, graduate programs. 2010. [Internet]. 2010-2011. Available from www.gwu.edu/bulletin/grad\hol.html.

[17] Gustafson DH, Cats-Baril WL, Alemi F. Systems to Support Health Policy Analysis : Theory, Models, and Uses. Ann Arbor, Mich.: Health Administration Press.1992.

[18] Habit. (n.d.). In Merriam-Webster's online dictionary. Awailable from http://www.merriam-webster.com/dictionary/habit

[19] Huntington JT, Dycus P, Hix C, West R, McKeon L, Coleman MT, ... \& Ogrinc G. A standardized curriculum to introduce novice health professional students to practice-based learning and improvement: A multi-institutional pilot study. Quality Management in Health Care. 2009; 18(3):174-81. PMid:17389285 http://dx.doi.org/10.1136/qshc.2007.024836

[20] Kripalani S, Yao X,Haynes RB. Interventions to enhance medication adherence in chronic medical conditions: A systematic review. Archives of Internal Medicine.2007; 167(6): 540-550. PMid:17389285 http://dx.doi.org/10.1001/archinte.167.6.540

[21] Kyrkjebo J, Hanasted BR. Personal improvement project in nursing education: learning methods and tools for continuous quality improvement in nursing practice. Journal of Advanced nursin.2003; 41(1): 88-98. http://dx.doi.org/10.1046/j.1365-2648.2003.02510.x

[22] Krykjebo JM, Hanssen TA,Haugland BO. Intoducing quality improvement to pre-qualification nursing students: evaluation of an experiential programme. Quality in Health Care. 2001; 10(4): 204-10. http://dx.doi.org/10.1136/qhc.0100204

[23] Lundeen E, Fisher-Pai E,Neuhauser D. Continuous self improvement to reduce stress levels: Developing an individualized model of health. Quality Management in Health Care.2001; 9(3): 47-56. PMid:11372503

[24] Matteson ML, Russell CL. Interventions to improve hemodialysis adherence: A systematic review of randomized controlled trials. Hemodialysis International. 2010: 14(4); 370-382. PMid:20796047

[25] Matteson ML. A pilot intervention to improve medication adherence in nonadherent inflammatory bowel disease patients. (Doctoral Dissertation). 2011. Awailable from ProQuest Dissertation \& Theses A \& I. (3514639).

[26] McDonald H, Garg A, Haynes RB. Interventions to enhance patient adherence to medication prescriptions: Scientific review. JAMA.2002; 288(22): 2868-2879. PMid:12472329 http://dx.doi.org/10.1001/jama.288.22.2868

[27] McLaughlin CP, Kaluzny AD. Continuous Quality Improvement in Health Care: Theory, Implementations, and Applications (3rd ed.). Subury, Massachusetts: Jones and Barlett Publishers. 2006.

[28] MEMS [apparatus and software]. Switzerland: AARDEX Group,. 2011. [Internet]. [cited 2011 Dec 1]. Available from http://www.aardexgroup.com/aardex_index.php?group=aardex\&id=99.

[29] Moore S. Using process improvement techniques to achieve health behavior change. 2003. [Internet]. 2003 [cited 2010 Dec 1]. Available 7/18/2010 from www.gunston.doit.gmu.edu.

[30] Oetker D, Cole C. Improving the outcome of emergency department patients with a chief complaint of chest pain. Journal of Nursing Care Quality.1996; 10(2): 58-74. http://dx.doi.org/10.1097/00001786-199601000-00009

[31] Peterson AM, Takiya L, Finley R. Meta-analysis of trials of interventions to improve medication adherence. American Journal of Health-System Pharmac.2003;60(7): 657-665. PMid:12701547

[32] Polit D, Beck CT. Nursing Research: Principles and Methods (7th ed.). Philadelphia, PA: Lippincott, Williams \& Wilkins; 2004.

[33] Ramirez O, Lawhon J. Quality improvement team uses FOCUS-PDCA method to reduce laboratory STAT volume and turnaround time. Clinical Laboratory Management Review.1994; 8(2): 130-141. PMid:10133983

[34] Riekert KA, Rand CS. Electronic monitoring of medication adherence: When is high-tech best? Journal of Clinical Psychology in Medical Settings.2002; 9(1): 25-34. http://dx.doi.org/10.1023/A:1014131928789

[35] Roter DL, Hall J, Merisca R, Nordstrom B, Cretin D, Svarstad B. Effectiveness of interventions to improve patient compliance: A meta-analysis. Medical Care. 1998; 36(8): 1138-1161.

PMid:9708588 http://dx.doi.org/10.1097/00005650-199808000-00004

[36] Russell CL, Conn VS, Ashbaugh C, Madsen R, Wakefield M, Webb A, Coffey D, Peace L.Taking Immunosuppressive Medications Effectively (TIMELink): A pilot randomized controlled trial in adult kidney transplant recipients. Clinical Transplantation. 2010. http://dx.doi.org/10.1111/j.1399-0012.2010.01358.x

[37] Russell CL, Ashbaugh C, Peace L, Centingok M, Hamburger K Q, Owens S, Coffey D, Webb A, Hathaway D, Winsett R P, Madsen R, Wakefield M. Time-in-a-Bottle (TIAB) study: Patterns, predictors, and outcomes of medication adherence in adult kidney transplant recipients (Under review).

[38] Russell CL. A clinical nurse specialist-led intervention to enhance medication adherence using the plan-do-check-act cycle for continuous self-improvement. Clinical Nurse Specialist.2010; 24(2): 69-75.

PMid:20168141 http://dx.doi.org/10.1097/NUR.0b013e3181cf554d

[39] Russell CL, Conn VS, Ashbaugh C, Madsen R, Hayes K, Ross G Jr. Intrasubject medication adherence patterns. Clinical Nursing Research. 2007; 16(2): 153-163. http://dx.doi.org/10.1177/1054773806296429 
[40] Russell CL, Ruppar T, Matteson ML (in press). Improving medication adherence: Moving from intention and motivation to a personal systems approach. Nursing Clinics of North America. PMid:21791262

[41] Sabaté E. Adherence to long-term therapies: Evidence for action. Geneva: World Health Organization; 2003.

[42] Schafer-Keller P, Lyon S, Van-Gelder F, De Geest S. A practical approach to promoting adherence to immunosuppressive medication after renal transplantation. Current Opinion in Nephrology and Hypertension.2006; 15(Clinical Update 2): S1-6.

[43] Schulz KF, Altman DG, Moher D. CONSORT 2010 statement: Updated guidelines for reporting parallel group randomised trials. British Medical Journal. 2010; 340: c332. http://dx.doi.org/ 10.1186/1741-7015-8-18

[44] Scott C. Applying 7-steps as a personal PDCA method. Center for Quality of Management Journal, Summer. 1993 : 5-14.

[45] Takemoto SK, Pinsky BW, Schnitzler MA, Lentine KL, Willoughby LM, Burroughs TE, Bunnapradist S. A retrospective analysis of immunosuppression compliance, dose reduction and discontinuation in kidney transplant recipients. American Journal of Transplantation, 2007; 7(12): 2704-2711. PMid:17868065 http://dx.doi.org/10.1111/j.1600-6143.2007.01966.x

[46] von Elm E, Altman DG, Egger M, Pocock SJ, Gotzsche PC, Vandenbroucke JP. Strengthening the Reporting of Observational Studies in Epidemiology (STROBE) statement: guidelines for reporting observational studies. British Medical Journal. 2007; 335(7624): 806-808. PMid:17947786 http://dx.doi.org/10.1136/bmj.39335.541782.AD

[47] Vokurka RJ. Using the Baldrige criteria for personal quality improvement. Industrial Management \& Data Systems. 2001; 101(7): 363-369. http://dx.doi.org/10.1108/EUM0000000005824

[48] Walton M. The Deming management method. New York, NY: The Putnam Publishing Group; 1986.

[49] Wong BM, Etchells EE, Kuper A, Levinson W, Shojania KG. Teaching quality improvement and patient safety to trainees: a systematic review. Academic Medicine. 2010; 85(9):1425-39. PMid:20543652

http://dx.doi.org/10.1097/ACM.0b013e3181e2d0c6 